\title{
PRODUÇÃO E DESEMPENHO DE SEMENTES DE CULTIVARES DE ALFACE EM DUAS ÉPOCAS DE PLANTIO ${ }^{1}$
}

\author{
ROSEANE PEREIRA VILLELA²; ROVILSON JOSÉ DE SOUZA ${ }^{3}$; RENATO MENDES GUIMARÃES ${ }^{3}$ \\ WARLEY MARCOS NASCIMENTO ${ }^{4}$; LUIZ ANTÔNIO AUGUSTO GOMES ${ }^{3}$; \\ BRUNO OLIVEIRA CARVALHO ${ }^{5}$; ANA CAROLINA ROSA BUENO ${ }^{6}$
}

\begin{abstract}
RESUMO - Estudos sobre a produção de sementes de alface em diferentes épocas de plantio podem fornecer subsídios para que o produtor utilize práticas adequadas de manejo, aumentando a possibilidade de sucesso no empreendimento, maximizando a produção e favorecendo o retorno econômico. As condições climáticas durante diferentes etapas de desenvolvimento das plantas podem exercer influência direta sobre o vigor das sementes produzidas. Sendo assim, objetivou-se, neste trabalho, avaliar oito cultivares de alface quanto à qualidade fisiológica e à produção de sementes em ambiente protegido, nas condições de primavera/verão e outono/inverno, na região de Lavras - MG. As plantas foram avaliadas com relação às épocas de pendoamento e antese e produção de sementes. Após a colheita e beneficiamento, as sementes foram pesadas e submetidas aos testes de germinação, primeira contagem de germinação, velocidade de germinação a 20, 25, 30 e $35^{\circ} \mathrm{C}$, emergência de plântulas e envelhecimento acelerado $\left(41^{\circ} \mathrm{C} / 48\right.$ e 72 horas). A produção de sementes de alface, na região de Lavras, em cultivo protegido deve ser realizada no outono/inverno para obtenção de maior produtividade e melhor qualidade das sementes, com utilização da cultivar Vera. A produção de sementes da cultivar Luisa no período do verão favorece sua capacidade de germinação sob condições de temperaturas elevadas. O plantio para produção de sementes das cultivares Lívia e Simpson na época primavera/verão e da cultivar Elisa na época outono/inverno não é recomendado para a região de Lavras - MG, por produzirem sementes de baixo vigor.
\end{abstract}

Termos para indexação: qualidade fisiológica, Lactuca sativa, germinação, vigor.

\section{LETTUCE SEED PRODUCTION AND PHYSIOLOGICAL QUALITY AT TWO DIFFERENT PLANTING DATES}

\begin{abstract}
Studies on lettuce seed production in different seasons may provide a better understanding for growers to use suitable management practices which could increase their production and maximize their profits. Environmental conditions during the different stages of plant and seed development may affect lettuce physiological seed quality. The objective of this study was to evaluate the performance of eight lettuce cultivars regarding seed production and seed physiological quality under greenhouse conditions in spring/ summer and in autumn/ winter at Lavras - MG region, Brazil. Plant tasselling, anthesis and seed production were evaluated. After harvesting and processing, seeds were weighed and evaluated for germination, first count, germination rate at $20,25,30$ and $35^{\circ} \mathrm{C}$,
\end{abstract}

${ }^{1}$ Aceito para publicação em 16/07/2009. Aceito para publicação em 07/12/2009. Parte da Tese de Doutorado pelo primeiro autor.

${ }^{2}$ Eng. Agr., DSc., Doutoranda em Fitotecnia, UFLA, Cx. Postal 37, 37.200-000, Lavras, MG; e-mail:roseagro@hotmail.com;

${ }^{3}$ Eng. Agr., DSc., Prof. Titular do Departamento de Agricultura da UFLA;
${ }^{4}$ Pesquisador Embrapa Hortaliças, CP 218, 70359-970 Brasília,DF; e-mail:wmn@cnph.embrapa.br;

${ }^{5}$ Eng. Agr., MSc., Mestrando em Fitotecnia, UFLA; brunoagroufla@hotmail.com;

${ }^{6}$ Eng. Agr., MSc., Mestranda em Fisiologia Vegetal, IAC (Instituto Agronômico de Campinas); e-mail:anacarolina_rosabueno@hotmail.com 
seedling emergence and accelerated aging $\left(41^{\circ} \mathrm{C} / 48\right.$ and 72 hours). The highest lettuce seed yield under greenhouse conditions was observed during the autumn/ winter season and higher yield and seed quality were obtained using the 'Vera' cultivar. However, seed production of the 'Luisa' cultivar during the summer increased germination at high temperatures. The 'Lívia' and 'Simpson' cultivars grown in the spring/ summer season and the 'Elisa' cultivar grown in the autumn/ winter season showed lower seed vigor.

Index terms: physiological quality, Lactuca sativa, germination, vigor.

\section{INTRODUÇÃO}

Poucos trabalhos foram conduzidos com o objetivo de fornecer informações dirigidas ao manejo de culturas olerícolas visando à produção de sementes. O manejo inadequado das culturas pode acarretar menor rentabilidade ou prejuízos, devido à obtenção de sementes de pior qualidade. Torna-se assim, de grande importância para produtores de sementes de hortaliças, que instituições de pesquisa desenvolvam trabalhos que gerem o conhecimento necessário para que ocorra uma melhoria na qualidade e na produtividade das sementes comercializadas. Nesse contexto, estudos sobre a produção de sementes de alface em diferentes épocas de semeadura podem proporcionar subsídios para melhorar a produtividade da cultura.

No Brasil, estão registrados atualmente no Serviço Nacional de Proteção de Cultivares - SNPC, 380 cultivares de alface (MAPA/ RNC, 2008) e, apesar da disponibilidade de cultivares nacionais, de características aceitáveis, e da existência de áreas extremamente favoráveis para a produção de sementes, poucos são os estudos realizados no sentido de avaliar as interações favoráveis do local e cultivar. Além disso, existe ainda uma grande dependência de importação de sementes, sendo que o Brasil importou, em 2005, 1.360,347 kg de sementes de alface (Nery et al., 2007).

A alface é uma planta anual, que sob dias longos e temperaturas elevadas tem induzida a etapa reprodutiva do ciclo da cultura, que se inicia com o pendoamento. A temperatura é o fator mais importante para o florescimento da alface; quando superior a $20^{\circ} \mathrm{C}$ estimula o pendoamento, que é intensificado à medida que a temperatura se eleva (Croda et al., 2008).

O ciclo das cultivares de alfaces, para a produção de sementes, varia em função do clima, cultivar e local, podendo alcançar 120 a 170 dias. Em cultivo protegido, esse período é reduzido para 100 a 120 dias (Menezes et al.,
2001). Os rendimentos são bastante variáveis dependendo da cultivar, do local de produção e das condições climáticas. A produtividade das cultivares pode variar de 372 a $1179 \mathrm{~kg} / \mathrm{ha}$ (Viggiano, 1990). Cada cultivar possui suas características principais e algumas distintas, podendo haver uma maior dificuldade para o pendoamento e a produção de sementes (Filgueira, 2003).

A utilização de sementes de alta qualidade fisiológica é pré-requisito para se alcançar um ótimo estabelecimento de plântulas e, consequentemente, para se obter alta produtividade. Sementes de alto potencial fisiológico são essenciais para que ocorra germinação rápida e uniforme, devido a sua influência no desempenho inicial das plantas (Marcos Filho, 1999).

A temperatura tem grande influência na germinação de sementes de alface, sendo que a ótima está em torno de $20^{\circ} \mathrm{C}$; as sementes da maioria das cultivares não germinam quando expostas as temperaturas superiores a $30^{\circ} \mathrm{C}$. A região geográfica onde as sementes de alface são produzidas afeta significativamente o desempenho das sementes. Independentemente do genótipo, sementes produzidas sob elevadas temperaturas durante a fase reprodutiva, tem melhor desempenho germinativo do que aquelas produzidas sob baixas temperaturas nessa mesma fase. Assim, a maturação das sementes sob temperaturas elevadas supera parcialmente o efeito inibitório de altas temperaturas durante a germinação (Nascimento, 2002).

Por essa razão, deve-se dirigir atenção especial à escolha da época mais adequada para a semeadura do campo de produção de sementes, procurando a coincidência entre as condições climáticas mais favoráveis e as exigências da planta nos seus diversos estádios de desenvolvimento (Viggiano, 1990).

Sementes consideradas vigorosas são mais efetivas na mobilização e utilização de suas reservas energéticas, resultando na emergência mais rápida e uniforme, além do desenvolvimento de plântulas normais sob diferentes 
condições de campo (Marcos Filho, 2005).

A avaliação da qualidade fisiológica de sementes para fins de semeadura e comercialização tem sido rotineiramente baseada no teste de germinação, que fornece resultados referentes às plântulas normais produzidas por um lote de sementes, de acordo com as recomendações das Regras para Análise de Sementes - RAS (Brasil, 1992). No entanto, o conhecimento do vigor das sementes poderá indicar com maior precisão seu potencial de desempenho no campo. Estudos sobre o vigor de sementes de alface têm indicado testes como o de envelhecimento acelerado em conjunto com a primeira contagem do teste de germinação e/ou comprimento da raiz primária, como parâmetros para a melhor escolha dos lotes de sementes (Franzin et al., 2004; Nascimento e Pereira, 2007).

Sendo assim, objetivou-se, neste trabalho, avaliar oito cultivares de alface quanto à qualidade fisiológica e à produção de sementes em ambiente protegido, nas condições de verão e inverno, na região de Lavras - MG.

\section{MATERIAL E MÉTODOS}

O experimento foi conduzido em casa de vegetação com armação de madeira coberta com plástico aditivado antiUV de 100 micras de espessura e $14 \mathrm{~m}$ de comprimento, 6 $\mathrm{m}$ de largura e 3,8 $\mathrm{m}$ de altura na parte mais alta e, um pé direito de 2,5 m; no Setor de Olericultura da Universidade Federal de Lavras-UFLA / MG.

Os genótipos utilizados para a produção de sementes foram: Regina 2000 (cultivar de folhas lisas, tolerante ao pendoamento precoce e ao calor, não forma cabeça, com ciclo de 70 a 80 dias), Livia (cultivar de folhas lisas, com tolerância à germinação sob condições de temperaturas elevadas, adaptada a regiões de clima quente; resistente ao vírus do mosaico da alface, com ciclo de aproximadamente de 65 dias), Babá de Verão (cultivar de folhas lisas, suporta temperaturas elevadas, com ciclo de 50 dias no verão e 70 dias no inverno), Luisa (cultivar de folhas lisas, resistente ao calor e pendoamento precoce, com ciclo de 70 a 80 dias), Elisa (cultivar de folhas lisas, alta uniformidade de campo e alta resistência ao pendoamento, alto nível de resistência ao vírus do mosaico da alface, estirpe 2, com ciclo de 65 a 75 dias), Verônica (cultivar de folhas crespas, tolerante ao pendoamento precoce, com ciclo de 60 a 70 dias) Vera (cultivar de folhas crespas, apresenta alta resistência ao pendoamento precoce, com ciclo de 60 a 70 dias) e Simpson (cultivar de folhas crespas, tolerante a temperaturas elevadas, com ciclo de 60 dias no verão e 80 dias no inverno).

Foram realizados dois cultivos, um no outono/inverno de 2007 e outro na primavera/verão de 2007/2008. As semeaduras ocorreram respectivamente nos meses de março e outubro em bandejas de poliestireno expandido (isopor) de 128 células, utilizando-se o substrato comercial Plantmax $^{\circledR}$, e duas a três sementes por célula. Após a germinação, quando as plântulas apresentaram o estádio de primeira folha definitiva, procedeu-se o desbaste, deixando apenas uma planta em cada célula até o término da fase de produção de mudas. Posteriormente, as plantas foram transplantadas para vasos (5 litros) com terra de subsolo, areia e esterco de codorna nas proporções de 50, 25 e $25 \%$, respectivamente e colocadas em casa vegetação, utilizando o sistema de fertirrigação por gotejamento. Foram anotadas, diariamente, as temperaturas máximas e mínimas nas alturas de $0,15 \mathrm{~m}$ e $2 \mathrm{~m}$ durante todas as etapas.. O espaçamento entre vasos foi de $0,80 \times 0,40 \mathrm{~m}$, sendo cada parcela composta de seis plantas.

Após o transplantio, as plantas foram medidas diariamente, sendo computada a data em que atingiram 40 $\mathrm{cm}$ de altura para determinação do inicio do pendoamento e também a data em que a primeira flor se abriu, para a determinação da antese.

O ponto de colheita foi determinado aos 10 dias após $60-70 \%$ das flores abertas (Menezes et al., 2001). As sementes foram colhidas manualmente, sendo cada inflorescência envolvida por um saco de papel, cortada e secada por 72 horas, em câmaras de circulação de ar, a $30{ }^{\circ} \mathrm{C}$, para facilitar a debulha durante o beneficiamento; posteriormente, foram separadas e limpas em peneiras.

O grau de umidade das sementes foi determinado pelo método de estufa a $105 \pm 3{ }^{\circ} \mathrm{C}$ por 24 horas (Brasil, 1992), com duas repetições. Os resultados foram expressos em porcentagem.

As sementes de cada seis plantas que constituíram as parcelas foram pesadas, sendo calculada a massa de sementes em $\mathrm{kg} / \mathrm{ha}$, de acordo com o número de plantas do espaçamento utilizado. Realizou-se ainda o cálculo da massa de mil sementes, segundo Brasil (1992).

Em seguida, as sementes foram secas novamente até atingirem a média de $6 \%$ de água, em câmaras de circulação de ar a $30{ }^{\circ} \mathrm{C}$, no Laboratório de Análise de Sementes da Universidade Federal de Lavras-UFLA/MG, onde foram submetidas às avaliações descritas a seguir:

Para a realização do teste de germinação a semeadura foi realizada com quatro repetições de 50 sementes em caixas de plástico transparente $(11,5 \times 11,5 \times 3,5 \mathrm{~cm})$ sobre duas folhas 
de papel de germinação germibox, previamente umedecidas com água destilada, em quantidade equivalente a 2,5 vezes a massa do papel. As sementes foram mantidas a 20, 25, 30 e 35 ${ }^{\circ} \mathrm{C}$. Foi determinada a porcentagem de germinação (emissão da raiz primária) sete dias após a semeadura.

A primeira contagem de germinação constituiu no registro da porcentagem de sementes germinadas (emissão da raiz primária) no quarto dia após a semeadura. $\mathrm{O}$ índice de velocidade de germinação foi calculado segundo a fórmula proposta por Maguire (1962), computando-se o número de sementes germinadas (raiz primária com, pelo menos, $1 \mathrm{~mm}$ de comprimento).

A emergência de plântulas foi avaliada em substrato solo e areia na proporção 1:2 em bandejas de plástico. A umidade do substrato foi ajustada para $60 \%$ da capacidade de retenção. Após a semeadura das quatro repetições de 50 sementes, as bandejas foram mantidas em germinadores a $20{ }^{\circ} \mathrm{C}$. A partir do início da emergência das plântulas foram realizadas avaliações diárias computando-se o número de plantas emergidas até a estabilização do estande. O índice de velocidade de emergência foi determinado segundo fórmula proposta por Maguire (1962).

Para o teste de envelhecimento acelerado foram utilizadas caixas de plástico (tipo gerbox) como compartimentos individuais (mini-câmaras), possuindo no interior uma bandeja com tela metálica, onde as sementes foram distribuídas de maneira uniforme. Dentro de cada caixa foram adicionados $40 \mathrm{~mL}$ de água destilada; caixas foram mantidas em câmara tipo BOD a $41^{\circ} \mathrm{C}$, durante períodos de 48 e 72 horas. Em seguida, as sementes foram submetidas ao teste de germinação, conforme descrito anteriormente, apenas a $20^{\circ} \mathrm{C}$, com contagem aos sete dias.
Foi utilizado o delineamento inteiramente casualizado com quatro repetições, para as variáveis de determinação do número de dias para inicio do pendoamento, da abertura da primeira flor, da massa de sementes em $\mathrm{kg} / \mathrm{ha}$, da massa de mil sementes, da porcentagem e da velocidade de emergência; os dados foram analisados em esquema fatorial 8x2 (8 genótipos, 2 épocas de produção). Para os testes de germinação, primeira contagem e índice de velocidade de germinação os dados foram analisados em esquema fatorial $8 \times 2 \times 4$ ( 8 genótipos, 2 épocas de produção e 4 temperaturas de incubação). No teste de envelhecimento acelerado os dados foram analisados em esquema fatorial $8 \times 2 \times 2$ ( 8 genótipos, 2 épocas de produção e 2 períodos de envelhecimento). Os dados foram submetidos à análise de variância e as médias comparadas entre si pelo teste de Scott-Knott, a 5\% de probabilidade. Sendo transformados os dados de porcentagem de germinação, primeira contagem, índice de velocidade de germinação, emergência, índice de velocidade de emergência e envelhecimento acelerado em raiz quadrada de $\mathrm{Y}+0.5$ - SQRT $(\mathrm{Y}+0.5)$. As análises estatísticas foram realizadas com auxílio do programa estatístico SISVAR ${ }^{\circledR}$, versão 4.0 (Ferreira, 2000).

\section{RESULTADOS E DISCUSSÃO}

De acordo com os dados climáticos no interior da casa de vegetação (Figura 1), a temperatura máxima durante o "inverno" (a semeadura realizada em março) variou de 20 a $45^{\circ} \mathrm{C}$ e a mínima de 5 a $19{ }^{\circ} \mathrm{C}$, enquanto que no "verão" (semeadura realizada em outubro) variou de 27 a $53{ }^{\circ} \mathrm{C}$ e a mínima de 13 a $30^{\circ} \mathrm{C}$. A diferença mais acentuada ocorreu na mínima, que foi mais alta no "verão".

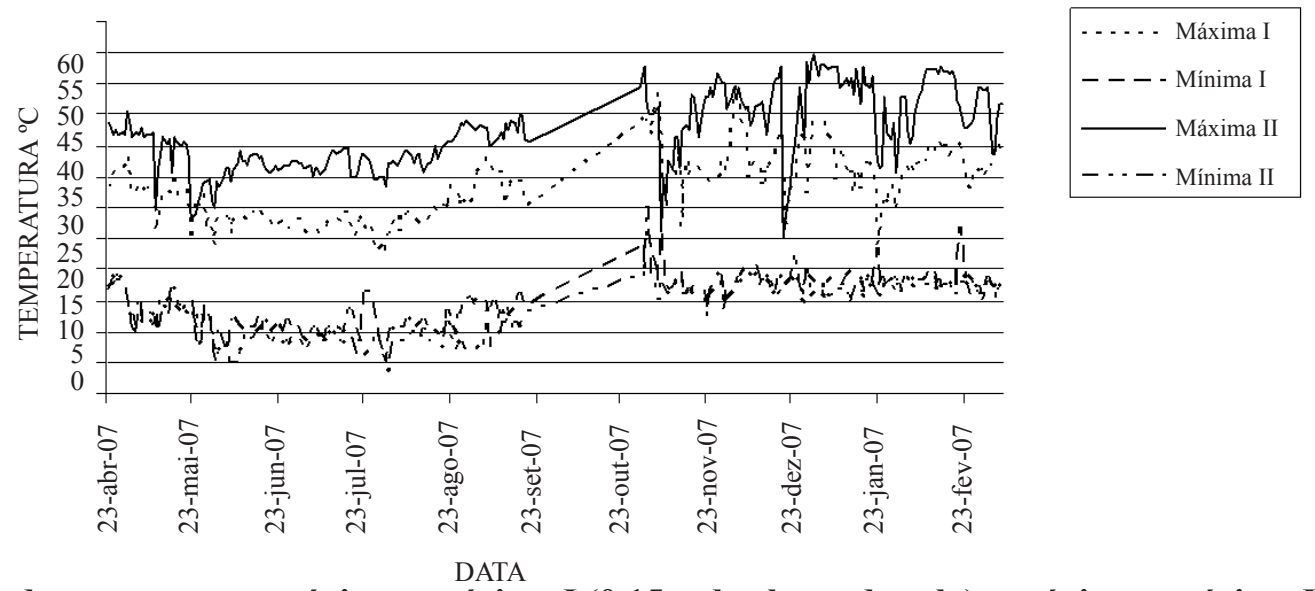

FIGURA 1. Média diária da temperatura máxima e mínima I (0,15m de altura do solo) e máxima e mínima II (2,0m de altura do solo), registrada no decorrer do período de produção de sementes de alface no inverno (2007) e no verão (2007/2008). 
A temperatura máxima variando entre 25 e $40{ }^{\circ} \mathrm{C}$ durante o período de outono/inverno, 20 dias antes do pendoamento, favoreceu o crescimento vegetativo das plantas de alface (Figura 2 e Tabela 1). No entanto, a temperatura máxima, mais elevada variando entre 25 e 53 ${ }^{\circ} \mathrm{C}$ (Figura 2) durante o cultivo de primavera/verão pode ter interferido na precocidade do pendoamento e florescimento das diferentes cultivares, uma vez que a temperatura é o fator mais importante para o pendoamento e florescimento da alface (Viggiano, 1990). Vale ressaltar que a amplitude das temperaturas observadas nas duas épocas, principalmente por causa das temperaturas máximas, é consequência do aquecimento que ocorre durante o dia nos cultivos protegidos sem controle de temperatura.

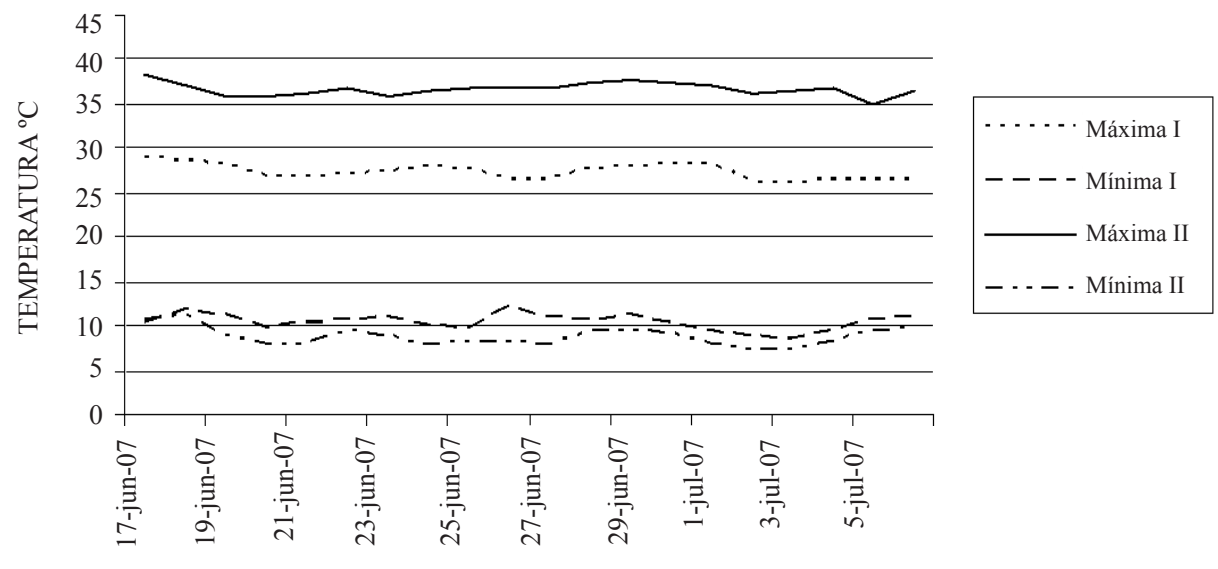

FIGURA 2. Média diária da temperatura máxima e mínima I (0,15m de altura do solo) e máxima e mínima II (2,0m de altura do solo), registrada 20 dias antes do período de pendoamento das plantas de alface no inverno (2007).

TABELA 1. Número de dias para o inicio do pendoamento (altura da planta $\geq 40 \mathrm{~cm}$ ) e abertura da primeira flor (antese) de cultivares de alface em duas épocas de produção.

\begin{tabular}{|c|c|c|c|c|}
\hline \multirow{3}{*}{ Cultivares } & \multicolumn{4}{|c|}{ Épocas de produção } \\
\hline & Verão & Inverno & Verão & Inverno \\
\hline & \multicolumn{2}{|c|}{ Pendoamento ( $\mathrm{n}^{\circ}$ de dias $)$} & \multicolumn{2}{|c|}{ Antese ( $n^{\circ}$ de dias) } \\
\hline Lívia & $79 \mathrm{Ab}$ & $108 \mathrm{Ba}$ & $96 \mathrm{Bb}$ & $142 \mathrm{Ba}$ \\
\hline Babá de Verão & $73 \mathrm{Bb}$ & $97 \mathrm{Da}$ & $95 \mathrm{Cb}$ & $126 \mathrm{Ca}$ \\
\hline Luisa & $78 \mathrm{Ab}$ & $110 \mathrm{Ba}$ & $100 \mathrm{Ab}$ & $140 \mathrm{Ba}$ \\
\hline Regina 2000 & $77 \mathrm{Ab}$ & $113 \mathrm{Aa}$ & $101 \mathrm{Ab}$ & 146 Aa \\
\hline Simpson & $68 \mathrm{Cb}$ & $88 \mathrm{Ea}$ & $94 \mathrm{Cb}$ & $115 \mathrm{Da}$ \\
\hline Elisa & $77 \mathrm{Ab}$ & $108 \mathrm{Ba}$ & $95 \mathrm{Cb}$ & $143 \mathrm{Ba}$ \\
\hline Vera & $76 \mathrm{Ab}$ & $112 \mathrm{Aa}$ & $97 \mathrm{Bb}$ & 146 Aa \\
\hline Verônica & $74 \mathrm{Bb}$ & $103 \mathrm{Ca}$ & $96 \mathrm{Bb}$ & $127 \mathrm{Ca}$ \\
\hline $\mathrm{CV}(\%)$ & \multicolumn{2}{|c|}{2,06} & \multicolumn{2}{|c|}{1,84} \\
\hline
\end{tabular}

Médias seguidas pela mesma letra minúscula na linha e maiúscula na coluna não diferem pelo teste de Scott-Knott a 5\% de probabilidade.

A cultivar Regina 2000 foi mais tardia quanto à abertura da primeira flor e ao pendoamento tanto no inverno quanto no verão, enquanto a cultivar Simpson foi mais precoce nas duas situações (Tabela 1). Dias longos associados a temperaturas elevadas, aceleram o processo o qual é também dependente da cultivar. Determinadas cultivares 
de verão, resistentes ao pendoamento precoce, podem apresentar certa dificuldade para pendoar e florescer, sendo algumas vezes necessário o uso de técnicas específicas para induzir o florescimento (Viggiano, 1990).

Entretanto não se pode correlacionar a precocidade da antese ao pendoamento, pois a cultivar Elisa foi uma das mais precoces na abertura da primeira flor (antese) e também uma das mais tardias no pendoamento em condições de verão (Tabela 1). Isso favorece tanto a sua produção comercial em regiões de clima quente, quanto a sua produção de sementes, tendo em vista que Viggiano (1990) recomendou a semeadura em épocas de temperaturas mais amenas, para que ocorra o favorecimento do crescimento da fase vegetativa antes do início da fase reprodutiva.

Temperaturas superiores a $20^{\circ} \mathrm{C}$ estimulam o pendoamento da alface, que é acentuado à medida que a temperatura aumenta. Dias longos associados a temperaturas elevadas aceleram o processo, o qual é também dependente da cultivar (Nagai, 1980; Viggiano, 1990). O início do alongamento da haste floral assinala o fim da fase vegetativa e o inicio da fase reprodutiva (Maluf, 1994). A ocorrência deste fenômeno varia entre cultivares, sendo as de pendoamento precoce (ou de inverno) impróprias para o cultivo em temperaturas mais elevadas, onde o processo é acelerado, Esse comportamento pode ser observado pela análise dos resultados das avaliações fisiológicas das sementes das cultivares estudadas nesse trabalho.

As cultivares produzidas no período de inverno foram mais produtivas que no verão, exceto a cultivar Verônica que apresentou maior produtividade de sementes no verão com 5,94 Kg/ha (Tabela 2). O clima mais ameno, com temperaturas médias mais baixas na época outono/inverno, pode ter favorecido o melhor desenvolvimento vegetativo contribuindo para uma maior produção de sementes. As maiores produtividades foram obtidas com as cultivares Vera $(1370,31 \mathrm{~kg} / \mathrm{ha})$ no outono/inverno e Simpson (1012,50 kg/ha) na primavera/verão. Sendo a cultivar Elisa a de menor produção de sementes no período do outono/ inverno.

TABELA 2. Massa de mil sementes (MMS) em gramas e massa da produção de sementes (MPS) em Kg/ha de cultivares de alface em duas épocas de produção.

\begin{tabular}{lccrr}
\hline \multirow{2}{*}{ Cultivares } & \multicolumn{4}{c}{ Épocas de produção } \\
\cline { 2 - 6 } & \multicolumn{2}{c}{ Verão } & Inverno & \multicolumn{2}{c}{ Verão } & \multicolumn{2}{c}{ Inverno } \\
\cline { 2 - 6 } & $0,72 \mathrm{Ab}$ & $1,13 \mathrm{Aa}$ & $396,88 \mathrm{~Gb}$ & $760,31 \mathrm{Ga}$ \\
\hline Lívia & $0,83 \mathrm{Ab}$ & $1,17 \mathrm{Aa}$ & $646,63 \mathrm{Db}$ & $870,31 \mathrm{Ea}$ \\
Babá de Verão & $0,98 \mathrm{Ab}$ & $1,18 \mathrm{Aa}$ & $499,38 \mathrm{~Eb}$ & $1217,19 \mathrm{Ba}$ \\
Luisa & $0,70 \mathrm{Ab}$ & $1,11 \mathrm{Aa}$ & $337,50 \mathrm{Hb}$ & $842,50 \mathrm{Fa}$ \\
Regina 2000 & $0,96 \mathrm{Ab}$ & $1,29 \mathrm{Aa}$ & $1012,50 \mathrm{Ab}$ & $1069,06 \mathrm{Ca}$ \\
Simpson & $0,95 \mathrm{Ab}$ & $1,15 \mathrm{Aa}$ & $455,00 \mathrm{Fb}$ & $650,94 \mathrm{Ha}$ \\
Elisa & $0,80 \mathrm{Aa}$ & $0,76 \mathrm{Ba}$ & $696,56 \mathrm{Cb}$ & $1370,31 \mathrm{Aa}$ \\
Vera & $0,78 \mathrm{Aa}$ & $0,96 \mathrm{Ba}$ & $975,94 \mathrm{Ba}$ & $911,56 \mathrm{Db}$ \\
Verônica & \multicolumn{3}{c}{1,84} \\
\hline \multicolumn{1}{c}{$\mathrm{CV}(\%)$} & 17,38 & & \multicolumn{3}{c}{} \\
\hline
\end{tabular}

Médias seguidas pela mesma letra minúscula na linha e maiúscula na coluna não diferem pelo teste de Scott-Knott a 5\% de probabilidade.

A cultivar Regina 2000 foi a menos produtiva no período do verão com apenas $337,50 \mathrm{~kg} / \mathrm{ha}$, no entanto, em cultivo protegido de outono/inverno sua produção foi de $842,50 \mathrm{~kg} / \mathrm{ha}$, (Tabela 2) e apesar de não apresentar alto rendimento em produção de sementes, com relação às outras cultivares, foi mais expressiva do que quando produzida por Menezes et al. (2001) em cultivo hidropônico, com rendimento de $633 \mathrm{~kg} / \mathrm{ha}$ e por Viggiano (1990) em cultivo convencional com $270 \mathrm{~kg} /$ ha. A massa de 1000 sementes variou de 0,70 a $1,29 \mathrm{~g}$, 
não apresentando diferenças significativas entre as cultivares com relação à produção de sementes na primavera/verão. A massa das sementes das cultivares produzidas no outono/ inverno foi maior que naquelas produzidas na primavera/ verão (Tabela 2). Entretanto, as sementes das cultivares Vera e Verônica apresentaram uma menor massa que as sementes das outras cultivares produzidas no inverno. $\mathrm{O}$ retardamento da fase reprodutiva em temperaturas amenas, com consequente aumento do período de desenvolvimento das plantas de alface, propicia a formação de um aparato fotossintético mais desenvolvido e, portanto capaz de produzir maior fluxo de fotoassimilados para as sementes que, por isso são formadas com maior tamanho e densidade.

O grau de umidade das sementes variou de $6,0 \%$ a $8,9 \%$ após serem colhidas, secas e beneficiadas; os valores médios foram de $8,2 \%$ e $6,7 \%$ para os cultivos de verão e inverno respectivamente (Tabela 3 ).

Independentemente da época de produção de sementes das oito cultivares avaliadas, o aumento da temperatura foi prejudicial à germinação das sementes, provavelmente devido à antecipação da floração e conseqüente redução do desenvolvimento da planta mãe e sua capacidade em nutrir a sementes (Tabela 4). Resultados semelhantes foram observados por Nascimento \& Pereira (2007) com a cultivar Everglades que teve a sua germinação acentuadamente reduzida quando incubada sob temperatura elevada $\left(35^{\circ} \mathrm{C}\right)$.

TABELA 3. Grau de umidade (U) de sementes de cultivares de alface em duas épocas de produção.

\begin{tabular}{|c|c|c|}
\hline \multirow{3}{*}{ Cultivares } & \multicolumn{2}{|c|}{ Épocas de produção } \\
\hline & Verão & Inverno \\
\hline & \multicolumn{2}{|c|}{$\mathrm{U}(\%)$} \\
\hline Lívia & 8,2 & 7,0 \\
\hline Babá de Verão & 8,2 & 6,0 \\
\hline Luisa & 7,6 & 6,5 \\
\hline Regina 2000 & 8,1 & 6,8 \\
\hline Simpson & 8,0 & 6,4 \\
\hline Elisa & 8,3 & 7,0 \\
\hline Vera & 8,5 & 7,3 \\
\hline Verônica & 8,9 & 6,5 \\
\hline Média & 8,2 & 6,7 \\
\hline
\end{tabular}

TABELA 4. Germinação (\%) sob temperaturas de $20,25,30$ e $35^{\circ} \mathrm{C}$ de sementes de diferentes cultivares de alface em duas épocas de produção.

\begin{tabular}{|c|c|c|c|c|c|c|c|c|}
\hline \multirow{3}{*}{$\begin{array}{l}\text { Cultivares/ } \\
\text { Temperatura }\end{array}$} & \multicolumn{8}{|c|}{ Épocas de Produção } \\
\hline & \multicolumn{4}{|c|}{ Inverno } & \multicolumn{4}{|c|}{ Verão } \\
\hline & $20{ }^{\circ} \mathrm{C}$ & $25^{\circ} \mathrm{C}$ & $30{ }^{\circ} \mathrm{C}$ & $35^{\circ} \mathrm{C}$ & $20{ }^{\circ} \mathrm{C}$ & $25^{\circ} \mathrm{C}$ & $30^{\circ} \mathrm{C}$ & $35^{\circ} \mathrm{C}$ \\
\hline Lívia & $100 \mathrm{Aa}$ & $96 \mathrm{Aa}$ & $4 \mathrm{Db}$ & $0 \mathrm{Ab}$ & $80 \mathrm{Ca}$ & $70 \mathrm{Cb}$ & $9 \mathrm{Dc}$ & $6 \mathrm{Bc}$ \\
\hline Babá de Verão & $100 \mathrm{Aa}$ & $100 \mathrm{Aa}$ & $6 \mathrm{Db}$ & $0 \mathrm{Ab}$ & $96 \mathrm{Aa}$ & $88 \mathrm{Ab}$ & $37 \mathrm{Bc}$ & $2 \mathrm{Bd}$ \\
\hline Luisa & $100 \mathrm{Aa}$ & $100 \mathrm{Aa}$ & $47 \mathrm{Bb}$ & $0 \mathrm{Ac}$ & $100 \mathrm{Aa}$ & $98 \mathrm{Aa}$ & $94 \mathrm{Aa}$ & $45 \mathrm{Ab}$ \\
\hline Regina 2000 & $100 \mathrm{Aa}$ & $100 \mathrm{Aa}$ & $42 \mathrm{Bb}$ & $0 \mathrm{Ac}$ & $84 \mathrm{Bb}$ & $93 \mathrm{Aa}$ & $42 \mathrm{Bc}$ & $7 \mathrm{Bd}$ \\
\hline Simpson & $100 \mathrm{Aa}$ & $100 \mathrm{Aa}$ & $25 \mathrm{Cb}$ & $0 \mathrm{Ac}$ & $75 \mathrm{Ca}$ & $66 \mathrm{Cb}$ & $29 \mathrm{Cc}$ & $1 \mathrm{Bd}$ \\
\hline Elisa & $100 \mathrm{Aa}$ & $99 \mathrm{Aa}$ & $30 \mathrm{Cb}$ & $0 \mathrm{Ac}$ & $84 \mathrm{Ba}$ & $80 \mathrm{Ba}$ & $24 \mathrm{Cb}$ & $2 \mathrm{Bc}$ \\
\hline Vera & $100 \mathrm{Aa}$ & $99 \mathrm{Aa}$ & $66 \mathrm{Ab}$ & $0 \mathrm{Ac}$ & $86 \mathrm{Bb}$ & $96 \mathrm{Aa}$ & $28 \mathrm{Cc}$ & $2 \mathrm{Bd}$ \\
\hline Verônica & $100 \mathrm{Aa}$ & $100 \mathrm{Aa}$ & $37 \mathrm{Bb}$ & $0 \mathrm{Ac}$ & $99 \mathrm{Aa}$ & $98 \mathrm{Aa}$ & $30 \mathrm{Cb}$ & $1 \mathrm{Bc}$ \\
\hline
\end{tabular}

Médias seguidas pela mesma letra minúscula na linha e maiúscula na coluna não diferem pelo teste de Scott-Knott a 5\% de probabilidade.

Para todas as cultivares, nas duas épocas de produção, a germinação foi igual ou maior que o padrão estabelecido para comercialização de sementes de alface $(80 \%)$ sob a temperatura $20^{\circ} \mathrm{C}$. Apenas na cultivar Simpson, a germinação das sementes foi de $75 \%$ quando produzidas na primavera/ verão (Tabela 4). Nas cultivares produzidas durante o período 
de outono/inverno os testes de germinação conduzidos a 20 e $25{ }^{\circ} \mathrm{C}$ não detectaram diferenças significativas. Os testes de primeira contagem e velocidade de germinação a $25^{\circ} \mathrm{C}$ (Tabelas 5 e 6) mostraram-se mais sensíveis, detectando diferenças entre as cultivares não acusadas pelo teste de germinação. Pelos resultados desses dois testes, o melhor desempenho fisiológico foi observado nas sementes da cultivar Veronica (Tabelas 5 e 6).

TABELA 5. Primeira contagem de germinação (\%) sob temperaturas de 20, 25, 30 e $35{ }^{\circ} \mathrm{C}$ de sementes de diferentes cultivares de alface em duas épocas de produção.

\begin{tabular}{|c|c|c|c|c|c|c|c|c|}
\hline \multirow{3}{*}{$\begin{array}{c}\text { Cultivares/ } \\
\text { Temperatura }\end{array}$} & \multicolumn{8}{|c|}{ Épocas de Produção } \\
\hline & \multicolumn{4}{|c|}{ Inverno } & \multicolumn{4}{|c|}{ Verão } \\
\hline & $20^{\circ} \mathrm{C}$ & $25^{\circ} \mathrm{C}$ & $30^{\circ} \mathrm{C}$ & $35^{\circ} \mathrm{C}$ & $20^{\circ} \mathrm{C}$ & $25^{\circ} \mathrm{C}$ & $30^{\circ} \mathrm{C}$ & $35^{\circ} \mathrm{C}$ \\
\hline Lívia & $100 \mathrm{Aa}$ & $83 \mathrm{Bb}$ & $2 \mathrm{Bc}$ & $0 \mathrm{Ac}$ & $60 \mathrm{Da}$ & $67 \mathrm{Ca}$ & $8 \mathrm{Cb}$ & $4 \mathrm{Bb}$ \\
\hline Babá de Verão & $100 \mathrm{Aa}$ & $98 \mathrm{Aa}$ & $1 \mathrm{Bb}$ & $0 \mathrm{Ab}$ & $94 \mathrm{Aa}$ & $87 \mathrm{Ba}$ & $12 \mathrm{Cb}$ & $1 \mathrm{Bc}$ \\
\hline Luisa & $100 \mathrm{Aa}$ & $81 \mathrm{Bb}$ & $18 \mathrm{Ac}$ & $0 \mathrm{Ad}$ & $100 \mathrm{Aa}$ & $98 \mathrm{Aa}$ & $66 \mathrm{Ab}$ & $25 \mathrm{Ac}$ \\
\hline Regina 2000 & $100 \mathrm{Aa}$ & $75 \mathrm{Bb}$ & $6 \mathrm{Bc}$ & $0 \mathrm{Ac}$ & $52 \mathrm{Dc}$ & $41 \mathrm{Db}$ & $12 \mathrm{Cc}$ & $4 \mathrm{Bc}$ \\
\hline Simpson & $100 \mathrm{Aa}$ & $100 \mathrm{Aa}$ & $5 \mathrm{Bb}$ & $0 \mathrm{Ab}$ & $73 \mathrm{Ca}$ & $64 \mathrm{Ca}$ & $15 \mathrm{Cb}$ & $1 \mathrm{Bc}$ \\
\hline Elisa & $100 \mathrm{Aa}$ & $98 \mathrm{Aa}$ & $6 \mathrm{Bb}$ & $0 \mathrm{Ab}$ & $82 \mathrm{Ba}$ & $78 \mathrm{Ba}$ & $8 \mathrm{Cb}$ & $2 \mathrm{Bb}$ \\
\hline Vera & $100 \mathrm{Aa}$ & $99 \mathrm{Aa}$ & $24 \mathrm{Ab}$ & $0 \mathrm{Ac}$ & $84 \mathrm{Bb}$ & $95 \mathrm{Aa}$ & $24 \mathrm{Bc}$ & $1 \mathrm{Bd}$ \\
\hline Verônica & $100 \mathrm{Aa}$ & $100 \mathrm{Aa}$ & $25 \mathrm{Ab}$ & $0 \mathrm{Ac}$ & $98 \mathrm{Aa}$ & $96 \mathrm{Aa}$ & $11 \mathrm{Cb}$ & $1 \mathrm{Bc}$ \\
\hline $\mathrm{CV}(\%)$ & \multicolumn{8}{|c|}{3,73} \\
\hline
\end{tabular}

Médias seguidas pela mesma letra minúscula na linha e maiúscula na coluna não diferem pelo teste de Scott-Knott a 5\% de probabilidade.

TABELA 6. Índice de velocidade de germinação (IVG) sob temperaturas de $20,25,30 \mathrm{e} 35{ }^{\circ} \mathrm{C}$ de sementes de diferentes cultivares de alface em duas épocas de produção.

\begin{tabular}{|c|c|c|c|c|c|c|c|c|}
\hline \multirow{3}{*}{$\begin{array}{l}\text { Cultivares/ } \\
\text { Temperatura }\end{array}$} & \multicolumn{8}{|c|}{ Épocas de Produção } \\
\hline & \multicolumn{4}{|c|}{ Inverno } & \multicolumn{4}{|c|}{ Verão } \\
\hline & $20^{\circ} \mathrm{C}$ & $25^{\circ} \mathrm{C}$ & $30^{\circ} \mathrm{C}$ & $35^{\circ} \mathrm{C}$ & $20^{\circ} \mathrm{C}$ & $25^{\circ} \mathrm{C}$ & $30^{\circ} \mathrm{C}$ & $35^{\circ} \mathrm{C}$ \\
\hline Lívia & $96,75 \mathrm{Aa}$ & $90,94 \mathrm{Aa}$ & $2,50 \mathrm{Cb}$ & $0 \mathrm{Ab}$ & $46,45 \mathrm{Da}$ & $36,93 \mathrm{Ca}$ & $5,38 \mathrm{Bb}$ & $1,41 \mathrm{Bb}$ \\
\hline Babá de Verão & $92,50 \mathrm{Aa}$ & $33,35 \mathrm{Bb}$ & $2,18 \mathrm{Cc}$ & $0 \mathrm{Ac}$ & $80,48 \mathrm{Ba}$ & $37,43 \mathrm{Cb}$ & $7,57 \mathrm{Bc}$ & $0,33 \mathrm{Bc}$ \\
\hline Luisa & $99,25 \mathrm{Aa}$ & $94,83 \mathrm{Aa}$ & $34,30 \mathrm{Bb}$ & $0,25 \mathrm{Ac}$ & 97,86Aa & $75,98 \mathrm{Ab}$ & $44,64 \mathrm{Ac}$ & $17,28 \mathrm{Ad}$ \\
\hline Regina 2000 & $93,00 \mathrm{Aa}$ & $87,61 \mathrm{Aa}$ & $7,58 \mathrm{Cb}$ & $0 \mathrm{Ab}$ & $44,92 \mathrm{Da}$ & $37,32 \mathrm{Ca}$ & $10,44 \mathrm{Bb}$ & $2,42 \mathrm{Bb}$ \\
\hline Simpson & $95,00 \mathrm{Aa}$ & 95,00Aa & $4,05 \mathrm{Cb}$ & $0,25 \mathrm{Ab}$ & $65,84 \mathrm{Ca}$ & $53,04 \mathrm{Bb}$ & $8,55 \mathrm{Bc}$ & $0,25 \mathrm{Bc}$ \\
\hline Elisa & $97,50 \mathrm{Aa}$ & $94,59 \mathrm{Aa}$ & $3,95 \mathrm{Cb}$ & $0 \mathrm{Ab}$ & $64,50 \mathrm{Ca}$ & $38,91 \mathrm{Cb}$ & $2,44 \mathrm{Bc}$ & $3,30 \mathrm{Bc}$ \\
\hline Vera & $99,50 \mathrm{Aa}$ & $95,50 \mathrm{Aa}$ & $48,93 \mathrm{Ab}$ & $0 \mathrm{Ac}$ & $81,42 \mathrm{Ba}$ & $54,33 \mathrm{Bb}$ & $17,16 \mathrm{Bc}$ & $0,33 \mathrm{Bd}$ \\
\hline Verônica & $99,25 \mathrm{Aa}$ & $98,88 \mathrm{Aa}$ & $25,23 \mathrm{Bb}$ & $0,25 \mathrm{Ac}$ & $94,56 \mathrm{Aa}$ & $84,72 \mathrm{Aa}$ & $10,48 \mathrm{Bb}$ & $0,16 \mathrm{Bb}$ \\
\hline CV (\%) & & & & & & & & \\
\hline
\end{tabular}

Médias seguidas pela mesma letra minúscula na linha e maiúscula na coluna não diferem pelo teste de Scott-Knott a 5\% de probabilidade. 
Pelos resultados do teste de primeira contagem de germinação conduzido a $20^{\circ} \mathrm{C}$, para as sementes produzidas durante o período de inverno em cultivo protegido (Tabela 5) não foi observada diferença significativa entre as cultivares. Este teste, apesar de ser considerado importante, por ser pouco trabalhoso e não exigir equipamentos ou infraestrutura específicos (Bhering et al., 2000), pode ter seus resultados afetados pelo fato da temperatura de $20{ }^{\circ} \mathrm{C}$ ser ideal para a germinação das sementes; nessa situação é possível a expressão da germinação e formação de plântulas normais, sem a interferência de deficiências fisiológicas leves, que poderiam ser detectados na germinação sob estresse. Estudos conduzidos com outras espécies, tais como algodão (Torres, 1998) e pimentão (Torres \& Minami, 2000), também indicaram baixa sensibilidade do teste de primeira contagem para estratificar lotes de sementes, principalmente, quando as diferenças de vigor são relativamente estreitas.

As sementes da cultivar Luisa foram mais vigorosas que das demais cultivares em quase todas as temperaturas de germinação utilizadas no teste de primeira contagem, excetuando na temperatura de $25{ }^{\circ} \mathrm{C}$, independentemente da época em que foram produzidas suas sementes (Tabela 5). Esse teste também foi capaz de diferenciar lotes de sementes de alface em função do vigor (Franzin et al., 2004; Nascimento \& Pereira, 2007), e de outras espécies, como cenoura (Spinola et al., 1998) e pepino (Bhering et al., 2000).

É evidente o decréscimo que ocorre na germinação e o vigor (Tabelas 5 e 6 ) das sementes de alface à medida que a temperatura de germinação se eleva. Temperaturas de $35^{\circ} \mathrm{C}$ foram extremamente prejudiciais à germinação de todas as cultivares produzidas no inverno. As sementes de alface produzidas no período do verão tiveram germinação favorecida sob temperaturas mais elevadas tais como 30 e $35^{\circ} \mathrm{C}$, quando comparadas às de inverno. Essa relação entre temperaturas elevadas no desenvolvimento das sementes e a subseqüente adaptação para germinar em temperaturas elevadas é observada em diversas pesquisas, embora nenhuma tenha elucidações definitivas sobre os mecanismos que envolvem esse fenômeno (Drew \& Brocklehurst, 1990; Steiner \& Opoku-Boateng, 1991). Nas tabelas 4, 5 e 6 observa-se os resultados de vigor mais altos e maiores porcentagens de germinação em sementes da cultivar Luisa submetidas a temperaturas de 30 e $35^{\circ} \mathrm{C}$. Outros autores também afirmam que sementes de alfaces produzidas em regiões de clima quente têm maiores porcentagens de germinação quando expostas as altas temperaturas, do que quando produzidas em clima frio (Damania, 1986; Harrington \& Thompson, 1952). No presente estudo, apesar de todas as cultivares terem sido produzidas em condições de altas temperaturas, nem todas germinaram satisfatoriamente em condições de estresse $\left(35^{\circ} \mathrm{C}\right)$, por isso, pode-se constatar a existência de variabilidade genética para esta característica.

Pelos resultados de percentagem e velocidade de emergência, observa-se que para as sementes da maioria das cultivares, o inverno foi a melhor época de produção de sementes de alface (Tabela 7). Os menores valores foram observados para as sementes das cultivares Lívia e Simpson quando produzidas no verão, e para 'Elisa' quando a produção de sementes ocorreu no inverno. Estas comparações entre o "verão" e o "inverno" podem ser confusas uma vez que as diferenças nas temperaturas, conforme descritas, não foram tão acentuadas.

A cultivar Vera além de apresentar alta produção de sementes durante o cultivo de inverno $1370,31 \mathrm{~kg} /$ ha (Tabela 2) também apresentou os maiores valores no envelhecimento acelerado, na percentagem e índice de velocidade de emergência (Tabela 7 e 8). Já as sementes da cultivar Simpson quando produzidas no período do verão, foram pouco vigorosas nos mesmos testes de envelhecimento e emergência, apesar de ter obtido a maior produção de sementes no verão $(1012,50 \mathrm{Kg} / \mathrm{ha}$.

Estudos realizados com alface (Franzin et al., 2004) e com outras espécies indicam que a emergência de plântulas pode ser usada na avaliação do potencial fisiológico de sementes, como feijão vigna (Bias et al., 1999), pimentão (Torres \& Minami, 2000) e cenoura (Tessarioli Neto, 2001). No presente trabalho, esse teste também foi eficiente para diferenciar o vigor das sementes e pode-se observar o vigor mais alto em sementes da cultivar Luisa. (Tabela 7).

Pelo teste de envelhecimento acelerado (Tabela 8), observa-se que houve estratificação dos lotes de sementes em função do vigor. $\mathrm{O}$ estresse imposto às sementes foi suficiente para selecionar, nas sementes produzidas no outono inverno, da cultivar Luisa como a de mais alto vigor e as sementes da cultivar Elisa como as de mais baixo vigor. Neste teste, assim como nos outros citados anteriormente, a melhor qualidade fisiológica das sementes foi observada quando as sementes foram produzidas no período do inverno; sementes das cultivares Luisa, Babá de Verão, Simpson, Vera e Verônica foram as que apresentaram as maiores valores nos testes de envelhecimento acelerado com 48 e 72 horas. Pode-se observar também que no envelhecimento acelerado durante o período de 72 horas houve uma maior estratificação 
do vigor entre as sementes das cultivares. Considerando que todas as sementes foram produzidas nas mesmas condições, isolando-se assim os efeitos do ambiente sobre o potencial fisiológico das sementes, pode-se afirmar que a estratificação observada é devida a sensibilidade do teste em distinguir a variabilidade genética das cultivares, relativa à resposta da germinação das sementes às condições ambientais de cultivo da planta mãe.

TABELA 7. Emergência (\%) e índice de velocidade de emergência (\%) de sementes de diferentes cultivares de alface em duas épocas de produção.

\begin{tabular}{lcccc}
\hline \multirow{2}{*}{$\begin{array}{c}\text { Cultivares/ } \\
\text { Épocas de Produção }\end{array}$} & \multicolumn{3}{c}{ Testes } \\
\cline { 2 - 5 } & Inverno & Verão & \multicolumn{2}{c}{ Índice de Velocidade de Emergência } \\
\cline { 2 - 5 } Lívia & $84 \mathrm{Ca}$ & $66 \mathrm{Db}$ & $34,50 \mathrm{Ca}$ & $16,50 \mathrm{Db}$ \\
Babá de Verão & $97 \mathrm{Aa}$ & $82 \mathrm{Bb}$ & $36,25 \mathrm{Ca}$ & $19,75 \mathrm{Cb}$ \\
Luisa & $99 \mathrm{Aa}$ & $98 \mathrm{Aa}$ & $44,75 \mathrm{Aa}$ & $31,75 \mathrm{Ab}$ \\
Regina 2000 & $89 \mathrm{Ba}$ & $71 \mathrm{Cb}$ & $30,00 \mathrm{Ca}$ & $10,25 \mathrm{~Eb}$ \\
Simpson & $100 \mathrm{Aa}$ & $65 \mathrm{Db}$ & $39,75 \mathrm{Ba}$ & $17,00 \mathrm{Db}$ \\
Elisa & $53 \mathrm{Db}$ & $70 \mathrm{Ca}$ & $19,25 \mathrm{Db}$ & $24,00 \mathrm{Ba}$ \\
Vera & $99 \mathrm{Aa}$ & $70 \mathrm{Cb}$ & $43,25 \mathrm{Aa}$ & $22,50 \mathrm{Bb}$ \\
Verônica & $96 \mathrm{Aa}$ & $98 \mathrm{Aa}$ & $41,00 \mathrm{Ba}$ & $30,00 \mathrm{Ab}$ \\
\hline CV $(\%)$ & & & & 2,34 \\
\hline
\end{tabular}

Médias seguidas pela mesma letra minúscula na linha e maiúscula na coluna não diferem pelo teste de Scott-Knott a 5\% de probabilidade.

TABELA 8. Envelhecimento acelerado (\%) durante 48 e 72 horas de sementes de diferentes cultivares de alface em duas épocas de produção.

\begin{tabular}{lcccc}
\hline \multirow{2}{*}{$\begin{array}{c}\text { Cultivares/ } \\
\text { Épocas de Produção }\end{array}$} & \multicolumn{3}{c}{ Envelhecimento $48 \mathrm{~h}$} & \multicolumn{2}{c}{ Envelhecimento $72 \mathrm{~h}$} \\
\cline { 2 - 5 } & Inverno & Verão & Inverno & Verão \\
\hline Lívia & $100 \mathrm{Aa}$ & $46 \mathrm{Fb}$ & $96 \mathrm{Ba}$ & $42 \mathrm{Db}$ \\
Babá de Verão & $100 \mathrm{Aa}$ & $96 \mathrm{Bb}$ & $97 \mathrm{Aa}$ & $92 \mathrm{Ab}$ \\
Luisa & $100 \mathrm{Aa}$ & $98 \mathrm{Ab}$ & $98 \mathrm{Aa}$ & $87 \mathrm{Bb}$ \\
Regina 2000 & $100 \mathrm{Aa}$ & $80 \mathrm{Db}$ & $96 \mathrm{Ba}$ & $43 \mathrm{Db}$ \\
Simpson & $100 \mathrm{Aa}$ & $68 \mathrm{~Eb}$ & $98 \mathrm{Aa}$ & $67 \mathrm{Cb}$ \\
Elisa & $69 \mathrm{Bb}$ & $78 \mathrm{Da}$ & $54 \mathrm{Cb}$ & $69 \mathrm{Ca}$ \\
Vera & $100 \mathrm{Aa}$ & $86 \mathrm{Cb}$ & $98 \mathrm{Aa}$ & $69 \mathrm{Cb}$ \\
Verônica & $100 \mathrm{Aa}$ & $99 \mathrm{Aa}$ & $98 \mathrm{Aa}$ & $92 \mathrm{Ab}$ \\
\hline CV $(\%)$ & & 0,80 & & 0,80 \\
\hline
\end{tabular}

Médias seguidas pela mesma letra minúscula na linha e maiúscula na coluna não diferem pelo teste de Scott-Knott a 5\% de probabilidade.

A partir dos dados observados, pode-se notar que alguns testes adotados nesse trabalho não foram eficazes para a determinação da qualidade fisiológica das sementes de alface. No entanto, através da combinação das informações proporcionadas pela comparação de médias, verificou-se que a maioria dos testes: - de germinação $\left(30^{\circ} \mathrm{C}\right)$, - primeira contagem $\left(25\right.$ e $\left.30^{\circ} \mathrm{C}\right)$, - velocidade de germinação $(25$ e 30 $\left.{ }^{\circ} \mathrm{C}\right)$, - porcentagem e índice de velocidade de emergência de plântulas e envelhecimento acelerado ( 72 horas), foi eficiente para a avaliação do potencial fisiológico das sementes de 
alface, auxiliando, desta forma, a conclusão nas condições desse trabalho, sobre a época de semeadura e cultivar mais adequados para a produção de sementes sob condição de cultivo protegido.

\section{CONCLUSÕES}

A produção de sementes de alface, na região de Lavras, em cultivo protegido deve ser realizada no outono/inverno para obtenção de maior produtividade e melhor qualidade das sementes, com utilização da cultivar Vera.

A produção de sementes da cultivar Luisa no período do verão favorece sua capacidade de germinação sob condições de temperaturas elevadas.

O plantio para produção de sementes das cultivares Lívia e Simpson na época primavera/verão e da cultivar Elisa na época outono/inverno não é recomendado para a região de Lavras - MG, por produzirem sementes de baixo vigor.

\section{REFERÊNCIAS}

BHERING, M.C.; DIAS, D.C.F.S.; GOMES, J.M.;BARROS, D.I. Métodos para avaliação do vigor de sementes de pepino. Revista Brasileira de Sementes, v.22, n.2, p.171-175, jul. 2000.

BIAS, A.L.F.; TILLMANN, M.A.A.; VILLELA, F.A.; ZIMMER, G. J. Métodos para avaliação da qualidade fisiológica de sementes de feijão vigna. Scientia Agricola, v.56, n.3, p.651-660, jul. 1999.

BRASIL. Ministério da Agricultura e Reforma Agrária. Secretaria Nacional de Defesa Agropecuária. Departamento Nacional de Produção Vegetal. Coordenação de Laboratório Vegetal. Regras para Análise de Sementes. Brasília, DF, 1992. 365p.

BRASIL. Ministério da Agricultura, Pecuária e Abastecimento. Registro nacional de cultivares. Disponível em: <http://www.agricultura.gov.br/>. Acesso em: 15 dez. 2008.

CRODA, M.D.; NASCIMENTO, W.M.; FREITAS, R.A.; MEDEIROS, K. A. Produção de sementes de alface nas condições do Distrito Federal e sua capacidade germinativa sob temperaturas elevadas. In: CONGRESSO BRASILEIRO DE OLERICULTURA, 48., 2008, Maringá. Resumos... Maringá: ABH. 1 CD-ROM. Disponível em: <http://www. abhorticultura.com.br/>. Acesso em: 20 nov. 2008.

DAMANIA, A.B. Inhibition of seed germination in lettuce at high temperature. Seed Research, v.14, p.177-184, 1986.

DREW, R.L.K.; BROCKLEHURST, P.A. Effects of temperature of mother-plant environment on yield and germination of seeds of lettuce (Lactuca sativa). Annals of Botany, v.66, n.1, p.63-71, July 1990.

FERREIRA, D. F. Análises estatísticas por meio do SISVAR para Windows ${ }^{\circledR}$ versão 4.0. In: REUNIÃO ANUAL DA REGIÃO BRASILEIRA DA SOCIEDADE INTERNACIONAL DE BIOMETRIA, 45., 2000, São Carlos. Programas e Resumos... São Carlos: UFSCAR, 2000. p.235.

FILGUEIRA, F.A.R. Novo manual de olericultura: agrotecnologia moderna na produção e comercialização de hortaliças. 3.ed. Viçosa, MG: UFV, 2003. 412p.

FRANZIN, S.M.; MENEZES, N.L. de; GARCIA, D.C.; WRASSE, C.F. Métodos para avaliação do potencial fisiológico de sementes de alface. Revista Brasileira de Sementes, v.26, n.2, p.63-69, dez. 2004.

HARRINGTON, J.F.; THOMPSON, R.C. Effect of variety and area of production on subsequent germination of lettuce seed at high temperature. Proceedings of American Society for Horticultural Science, v.59, p.445-450, 1952.

MAGUIRE, J. D. Speed of germination-aid in selection and evaluation for seedling emergence and vigor. Crop Science, v.2, n.1, p.176-177, Jan./Feb. 1962.

MALUF, W.R. Melhoramento genético da alface (Lactuca sativa L.). In: MELHORAMENTO GENÉTICO DE HORTALIÇAS. Lavras: UFLA, 1994. 189p. (Apostila).

MARCOS FILHO, J. Fisiologia de sementes de plantas cultivadas. Piracicaba: FEALQ, 2005. 495p.

MARCOS FILHO, J. Testes de vigor: importância e utilização. In: KRZYZANOWSKI, F. C.; VIEIRA, R. D.; FRANÇA NETO, J. B. Vigor de sementes: conceitos e testes. Londrina: ABRATES, 1999. p.1-21.

MENEZES, N.L. de; SANTOS, O.S. dos; SCHMIDT, D. Produção de sementes de alface em cultivo hidropônico. Ciência Rural, v.31, n.4, p.705-706, jul. 2001.

NAGAI, H. Obtenção de novas cultivares de alface (Lactuca sativa L.) resistentes ao mosaico e ao calor: Brasil-303 e 311. Revista de Olericultura, v.18, p.14-21, 1980.

NASCIMENTO, W.M. Germinação de sementes de alface. Brasília, DF: Embrapa Hortaliças, 2002. 10p. (Embrapa Hortaliças. Circular Técnica, 29).

NASCIMENTO, W.M.; PEREIRA, R.S. Testes para avaliação do potencial fisiológico de sementes de alface. 
Revista Brasileira de Sementes, v.29, n.3, p.175-179, 2007.

NERY, M.C.; NERY, F.C.; GOMES, L.A.A. O mercado e a participação de sementes de hortaliças no Brasil. 2007. Disponível em: <http://www.infobibos.com/Artigos/2007_1/ sementes/index.htm>. Acesso em: 10 dez. 2008.

SPINOLA, M.C.M.; CALIARI, M.F.; MARTINS, L.; TESSAROLI NETO, J. Comparação entre métodos para avaliação do vigor de sementes de cenoura. Revista Brasileira de Sementes, v.20, n.2, p.301-395, jul. 1998.

STEINER, J.J.; OPOKU-BOATENG, K. Natural seasonlong and diurnal temperature effects on lettuce seed production and quality. Journal of the American Society for Horticultural Science, v.116, n.3, p.396-400, 1991.
TESSARIOLI NETO, J. Qualidade fisiológica e tamanho de sementes de cenoura. Scientia Agricola, v.58, n.1, p.201204, jan. 2001.

TORRES, S. B. Comparação entre testes de vigor para avaliar a qualidade fisiológica de sementes de algodão. Revista Brasileira de Sementes, v.20, n.2, p.249-253, jul. 1998.

TORRES, S. B.; MINAMI, K. Qualidade fisiológica das sementes de pimentão. Scientia Agricola, v.57, n.1, p.109112, jan. 2000.

VlGGiANO, J. Produção de sementes de alface. In: CASTEllane, P. D. (Ed.). Produção de sementes de hortaliças. Jaboticabal: FCAV/FUNEP, 1990. p.1-15. 